\title{
Endoscope-assisted management of sagittal synostosis: wide vertex suturectomy and barrel stave osteotomies versus narrow vertex suturectomy
}

\author{
Brian J. Dlouhy, MD, ${ }^{1}$ Dennis C. Nguyen, MD, ${ }^{2}$ Kamlesh B. Patel, MD, ${ }^{2}$ \\ Gwendolyn M. Hoben, MD, PhD, ${ }^{2}$ Gary B. Skolnick, BA, ${ }^{2}$ Sybill D. Naidoo, PhD, RN, CPNP, ${ }^{2}$ \\ Albert S. Woo, MD, ${ }^{2}$ and Matthew D. Smyth, MD1 \\ 1Division of Pediatric Neurosurgery, Department of Neurosurgery, and 2Division of Plastic and Reconstructive Surgery, \\ Department of Surgery, Washington University, St. Louis Children's Hospital, St. Louis, Missouri
}

\begin{abstract}
OBJECTIVE Endoscope-assisted methods for treatment of craniosynostosis have reported benefits over open calvarial vault reconstruction. In this paper, the authors evaluated 2 methods for endoscope-assisted correction of sagittal synostosis: wide vertex suturectomy and barrel stave osteotomies (WVS+BSO) and narrow vertex suturectomy (NVS).

METHODS The authors evaluated patients with nonsyndromic sagittal synostosis treated with either wide vertex suturectomy (4-6 cm) and barrel stave osteotomies (WVS+BSO) or narrow vertex suturectomy (NVS) (approximately $2 \mathrm{~cm}$ ) between October 2006 and July 2013. Prospectively collected data included patient age, sex, operative time, estimated blood loss (EBL), postoperative hemoglobin level, number of transfusions, complications, and cephalic index. Fourteen patients in the NVS group were age matched to 14 patients in the WVS+BSO group. Descriptive statistics were calculated, and Student t-tests were used to compare prospectively obtained data from the WVS+BSO group with the NVS group in a series of univariate analyses.

RESULTS The mean age at surgery was 3.9 months for WVS+BSO and 3.8 months for NVS. The mean operative time for patients undergoing NVS was 59.0 minutes, significantly less than the 83.4-minute operative time for patients undergoing WVS+BSO ( $\mathrm{p}$ 0.05). The differences in mean EBL (NVS: $25.4 \mathrm{ml}$; WVS+BSO: $27.5 \mathrm{ml})$, mean postoperative hemoglobin level (NVS: $8.6 \mathrm{~g} / \mathrm{dl}$; WVS+BSO: $8.0 \mathrm{~g} / \mathrm{dl}$ ), mean preoperative cephalic index (NVS: 69.9; WVS+BSO: 68.2), and mean cephalic index at 1 year of age (NVS: 78.1; WVS+BSO: 77.2) were not statistically significant.

CONCLUSIONS The NVS and WVS+BSO produced nearly identical clinical results, as cephalic index at 1 year of age was similar between the 2 approaches. However, the NVS required fewer procedural steps and significantly less operative time than the WVS+BSO. The NVS group obtained the final cephalic index in a similar amount of time postoperatively as the WVS+BSO group. Complications, transfusion rates, and EBL were not different between the 2 techniques. http://thejns.org/doi/abs/10.3171/2016.6.PEDS1623
\end{abstract}

KEY WORDS craniosynostosis; endoscopic; sagittal synostosis; suturectomy; minimally invasive; craniofacial

$\mathrm{N}$ UMEROus techniques have been developed to treat sagittal synostosis since Lane's original description of the strip craniectomy in $1892 .{ }^{8}$ The endoscope-assisted craniectomy (EAC) technique for treatment of craniosynostosis, first pioneered by Jimenez and Barone and reported in the literature in $1998,{ }^{3}$ has reported benefits over open calvarial vault reconstruction when performed in the first 6 months of life. The EAC technique has shown decreases in operative time, blood loss, transfusion requirements, cost, and hospital stays. , $^{1,-6,11-13}$ Postoperatively, the infants wear custom-made cranial molding helmets to augment the reshaping of their calvaria. ${ }^{6}$

ABBREVIATIONS EAC = endoscope-assisted craniectomy; EBL = estimated blood loss; NVS = narrow vertex suturectomy; $W V$ S+BSO = wide vertex suturectomy and barrel stave osteotomies.

SUBMITTED January 12, 2016. ACCEPTED June 28, 2016.

INCLUDE WHEN CITING Published online September 9, 2016; DOI: 10.3171/2016.6.PEDS1623. 
The EAC method for treatment of sagittal synostosis has 2 variations. The approach proposed by Jimenez and Barone relies on an endoscope-assisted wide $(4-6 \mathrm{~cm})$ vertex craniectomy of the sagittal suture in addition to biparietal and bitemporal "barrel-stave" or wedge osteotomies. ${ }^{3,5,7}$ A second approach reported by Ridgway et al. relies on less bone removal through an endoscope-assisted narrow (approximately $2 \mathrm{~cm}$ ) strip vertex craniectomy.1,11 Both use postoperative cranial molding helmets and have shown effectiveness in treating sagittal synostosis. However, no study has directly compared the techniques. Here, we evaluated these 2 techniques for endoscope-assisted correction of sagittal synostosis-wide vertex suturectomy and barrel stave osteotomies (WVS+BSO) and narrow vertex suturectomy (NVS) - and compared variables associated with surgery and clinical outcomes.

\section{Methods \\ Patient Population}

This was an age-matched retrospective study with the data collected in a prospective manner. Fourteen patients with isolated sagittal synostosis underwent NVS during the period from January 2012 to July 2013. These patients were age matched to 14 patients with isolated sagittal synostosis who had undergone wide vertex suturectomy and barrel stave osteotomies (WVS+BSO) at our institution from October 2006 to September 2011. Preoperative and postoperative clinical data have been prospectively collected at our institution since 2003. All patients underwent postoperative molding helmet therapy and were treated by a multidisciplinary team consisting of both a neurosurgeon (M.D.S.) and plastic surgeon (either K.B.P. or A.S.W.). Data collected included patient age, sex, operating time, estimated blood loss (EBL), postoperative hemoglobin, number of transfusions, complications, and cephalic index. Three-dimensional photographs were used to assess head shape preoperatively and postoperatively. The cephalic index was calculated as the ratio of the biparietal diameter to the anteroposterior diameter as measured by direct caliper measurements. The overall institutional goal cranial index for surgical repair of sagittal synostosis is 80 . The Washington University institutional review board approved this study.

\section{Surgical Technique}

Wide Vertex Suturectomy and Barrel Stave Osteotomies

WVS+BSO was performed as described by Jimenez et al. 3,7 After induction of general endotracheal tube anesthesia, the patient was placed in the modified "sphinx" position, frequently with the use of a DORO headrest (Pro Med Instruments). Two transverse incisions were made: a 2-cm incision posterior to the anterior fontanelle and a $2-\mathrm{cm}$ incision anterior to the lambda. After subgaleal dissection between the anterior fontanelle and lambda, bur holes and transverse osteotomies across the sagittal sinus were made at each incision using a high-speed drill and Kerrison rongeurs. The anterior osteotomy was connected to the anterior fontanelle with Mayo scissors, which allowed access to the epidural space with the endoscope. The endoscope was inserted into the epidural space to vi- sualize dissection of the dura and sagittal sinus from the overlying fused suture. With the aid of the endoscope, a 4- to 6-cm-wide vertex craniectomy was performed using Mayo scissors. Bilateral osteotomies are performed using scissors posterior to each coronal suture and anterior to each lambdoid suture, down to the squamosal suture inferiorly. The endoscope was used to visualize the cut bone edges to allow for coagulation using a suction/cautery device set at $50 \mathrm{~W}$. After hemostasis, the skin was closed in layers using absorbable suture.

\section{Narrow Vertex Suturectomy}

The NVS was performed as described by Ridgway et al. ${ }^{11}$ The surgery was performed similarly to the WVS+BSO technique, except a 2-cm-wide vertex suturectomy and no bilateral barrel stave osteotomies were performed.

\section{Helmeting}

Helmeting remained the same with both techniques. Postoperatively, the child was fitted for his or her first helmet in a series of 2-3 cranial molding helmets. The child wore the cranial molding helmets 23 hours per day. It was only taken off to clean the helmet and check the incision sites several times per day. Patients living locally used a helmet manufactured by a local orthotic provider. Patients who lived outside of the St. Louis metropolitan area were referred to local offices of a national orthotics provider (Hanger Orthotics) for molding helmet therapy. A nurse practitioner (S.N.) monitored the patients for compliance every 1-3 months until termination of helmet therapy at approximately 1 year of age. Because cohorts were age matched and helmeting was continued until 1 year of age, there was no statistically significant difference in helmeting time. All patients underwent 3D low-radiation-protocol head CT as an outpatient at 1 year of age.

\section{Statistical Analysis}

The 14 patients in the NVS group were age matched to 14 patients in the WVS+BSO group. Descriptive statistics were calculated, and Student $\mathrm{t}$-tests were used to compare prospectively obtained data from the WVS+BSO group with the NVS group in a series of univariate analyses (Microsoft Excel 2010). The significance value was predetermined at $\mathrm{p}<0.05$.

\section{Results \\ Patient Population}

Fourteen patients underwent NVS from January 2012 to July 2013. Fourteen patients who underwent WVS+BSO during the period from October 2006 to September 2011 were aged matched to the NVS group. The average age of the NVS group was 3.8 months (range 2.1-6.5 months) and consisted of 10 males and 4 females (Table 1). The average age of the WVS+BSO group was 3.9 months (range 2.1-6.6 months) and similarly consisted of 10 males and 4 females (Table 1).

\section{Surgical Procedures}

The 14 patients in the NVS group were compared with 
TABLE 1. Demographic characteristics and surgical and clinical outcomes for NVS and WVS+BSO

\begin{tabular}{|c|c|c|c|}
\hline Characteristic & WVS+BSO & NVS & $p$ Value \\
\hline No. of patients & 14 & 14 & \\
\hline Age in mos & & & 0.96 \\
\hline Mean & 3.9 & 3.8 & \\
\hline Range & $2.1-6.6$ & $2.1-6.5$ & \\
\hline Sex (F/M), no. & $4 / 10$ & $4 / 10$ & \\
\hline Operative time in mins & & & 0.001 \\
\hline Mean & 83.4 & 59 & \\
\hline Range & $63-132$ & $37-90$ & \\
\hline $\mathrm{EBL}$ in $\mathrm{ml}$ & & & 0.60 \\
\hline Mean & 28 & 25 & \\
\hline Range & $10-60$ & $15-40$ & \\
\hline Preop hemoglobin ( $\mathrm{g} / \mathrm{dl})$ & & & 0.59 \\
\hline Mean & 10.1 & 9.8 & \\
\hline Range & $9-12.1$ & $9-11.6$ & \\
\hline Postop hemoglobin (g/dl) & & & 0.24 \\
\hline Mean & 8.0 & 8.6 & \\
\hline Range & $5.5-11.9$ & $7.2-10.4$ & \\
\hline No. of transfusions & $1(7)$ & 0 & 0.33 \\
\hline Preop cephalic index & & & 0.27 \\
\hline Mean & 68.2 & 69.9 & \\
\hline Range & $63-75$ & $62-78$ & \\
\hline Postop cephalic index & & & 0.60 \\
\hline Mean & 77.2 & 78.1 & \\
\hline Range & $72-86$ & $73-85$ & \\
\hline
\end{tabular}

their age-matched cohorts in the WVS+BSO group in terms of operative time, EBL, postoperative hemoglobin level, number of transfusions, and complications (Table 1 and Fig. 1). The mean operative time for patients undergoing NVS was 59.0 minutes, significantly less than the 83.4-minute operative time for patients undergoing WVS+BSO ( $<$ 0.05). The mean EBL for patients undergoing NVS was $25.4 \mathrm{ml}$, which was not statistically significantly different from the mean EBL for patients undergoing WVS+BSO $(27.5 \mathrm{ml})$. The mean postoperative hemoglobin level was $8.6 \mathrm{~g} / \mathrm{dl}$ (range $7.2-10.4 \mathrm{~g} / \mathrm{dl}$ ) for the NVS group, which was not statistically significantly different from $8.0 \mathrm{~g} / \mathrm{dl}$ (range 5.5-11.9 g/dl) for the WVS+BSO group. No patient in the NVS group required a transfusion, and 1 patient (7\%) in the WVS+BSO group required a postoperative transfusion due to a decreasing hemoglobin level below $8 \mathrm{~g} / \mathrm{dl}$, with the patient becoming symptomatic. There were no surgery-related complications in either group.

\section{Surgical Outcomes}

Each infant was evaluated and fit for a cranial molding helmet in the perioperative period and monitored until 1 year of age. The cephalic index was obtained preoperatively and then postoperatively at 1-month intervals until 1 year of age (Table 1 and Figs. 1 and 2). The mean preoperative cephalic index was 69.9 in the NVS group, which was not statistically significantly different from a cephalic index of 68.2 in the WVS+BSO group (Table 1). The average cephalic index at 1 year of age was 78.1 in the NVS group, which was not significantly different from an average cephalic index of 77.2 in the WVS+BSO group. Just as the postoperative cephalic index at 1 year of age was not different between the groups, there was no statistically significant difference in the postoperative monthly cephalic indices between the groups in the immediate months following surgery. The WVS+BSO group obtained the final cephalic index in a similar amount of time postoperatively as the NVS group (Fig. 2). Helmet therapy continued until 1 year of age for all patients in each cohort, and thus helmeting time was not significantly different between the groups. Three-dimensional CT representative examples of isolated sagittal synostosis before and after treatment with WVS+BSO and NVS are shown in Fig. 3.

\section{Discussion}

Sagittal synostosis has been treated using various surgical methods. ${ }^{2,5,9,10}$ Comparing operative approaches is important to determine the best treatment strategy for each patient. Here, we compared NVS and WVS+BSO to determine if there was any difference in operative and clinical outcomes. We found that the mean operative time for NVS was $29 \%$ less than the average operative time for WVS+BSO $(\mathrm{p}<0.05)$. There was no difference in EBL, postoperative hemoglobin level, and complications between the 2 endoscope-assisted procedures. Both procedures achieved a similar clinical outcome upon completion of molding helmet therapy. The average cephalic index at postoperative follow-up at 1 year of age for each method was nearly the same. No difference in cephalic index each month postoperatively was noted between the WVS+BSO and NVS groups.

The difference in length of procedure between the 2 techniques was not unexpected since the NVS requires less tissue dissection and less bone removal than the WVS+BSO. With only a 2-cm-wide suturectomy, less subgaleal soft-tissue dissection is needed in the NVS compared with the 4- to 6-cm-wide suturectomy in the WVS+BSO. The WVS+BSO also utilizes multiple barrel-stave osteotomies. This requires more subgaleal softtissue dissection in addition to the added time for barrelstave osteotomies.

Interestingly, the EBL and postoperative hemoglobin levels were not significantly different between the 2 methods. Although the WVS+BSO required more dissection and osteotomies, most bleeding occurred from the dura overlying the sagittal sinus and from the diploe of the bone after suturectomy. Therefore, the size of the suturectomy did not significantly affect blood loss. The majority of the blood loss for the procedure presumably ended once the dural bleeding was controlled and the bone edges were cauterized.

The final clinical outcomes were unchanged between the 2 techniques. The cephalic index for the NVS was similar to that for the WVS+BSO at 1 year of age. The WVS+BSO group reached the final cephalic index in a similar time frame as the NVS cohort. Substantially more 

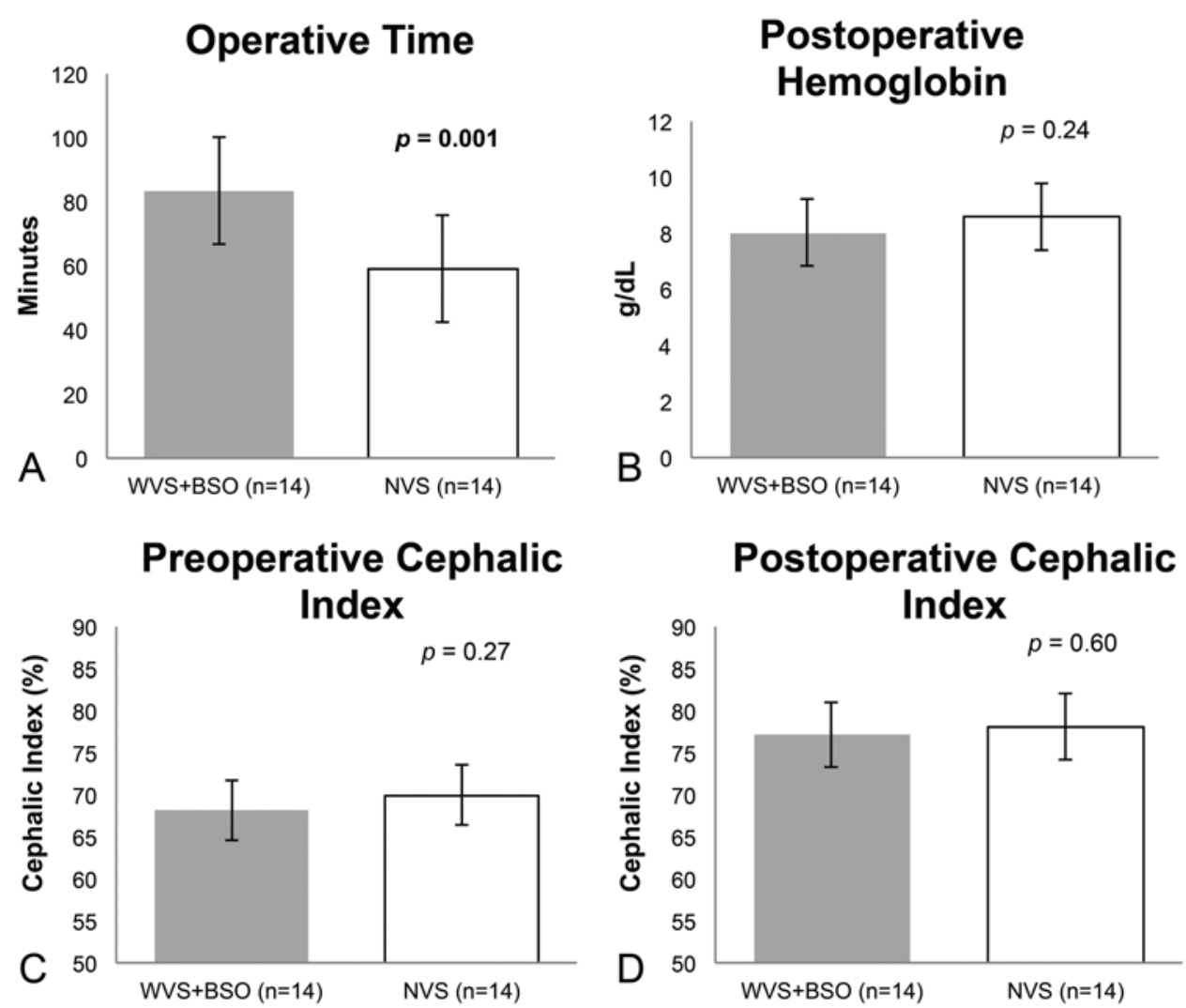

FIG. 1. Comparison of operative time, postoperative hemoglobin, and preoperative and postoperative cephalic indices between WVS+BSO and NVS. A: Operative time was significantly decreased in the NVS group compared with the WVS+BSO group. B-D: The postoperative hemoglobin level (B), preoperative cephalic index (C), and postoperative cephalic index (D) were not significantly different between the groups. Error bars are standard deviation.

bone is removed for WVS+BSO than for NVS and therefore less redirected brain growth is needed postoperatively, but this did not seem to affect cephalic index outcomes. In cases in which the parents were compliant with follow-up

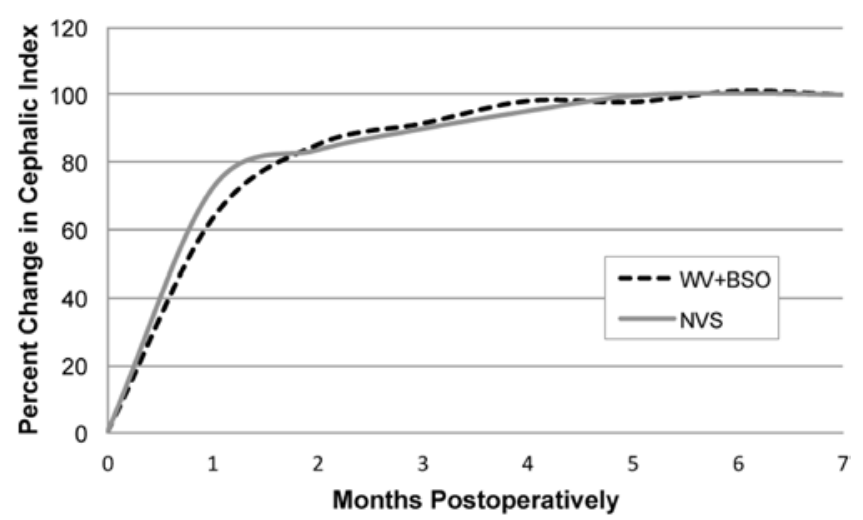

FIG. 2. Percentage of final cephalic index each month postoperatively until 1 year of age. The percentage of the final cephalic index was calculated as the difference between the cephalic index each month postoperatively and the final cephalic index at 1 year of age divided by the final cephalic index at 1 year of age. The WVS+BSO group obtained the final cephalic index in a similar amount of time postoperatively as the NVS group. One patient in the NVS group was excluded as an outlier. appointments and conscientious about ensuring the child wear the helmet 23 hours a day, the outcomes between the 2 procedures appeared to be the same. In both groups, the families and orthotists were counseled regarding aggressive helmeting therapy, and this was closely supervised by our center during the follow-up period to ensure a good correction.

\section{Limitations}

This was a single-center study, and the numbers were small. Therefore, the results found here may differ from results found in comparable studies performed at other institutions. Although the data were collected prospectively, the analysis was conducted in a retrospective manner.

\section{Conclusions}

The NVS and WVS+BSO methods produced nearly identical clinical results, as the cephalic index at 1 year of age was similar between the 2 approaches. However, the NVS required fewer procedural steps and significantly less operative time than the WVS+BSO. The WVS+BSO group obtained the final cephalic index in a similar amount of time postoperatively as the NVS group. Complications, transfusion rates, and EBL were not different between the 2 techniques. 

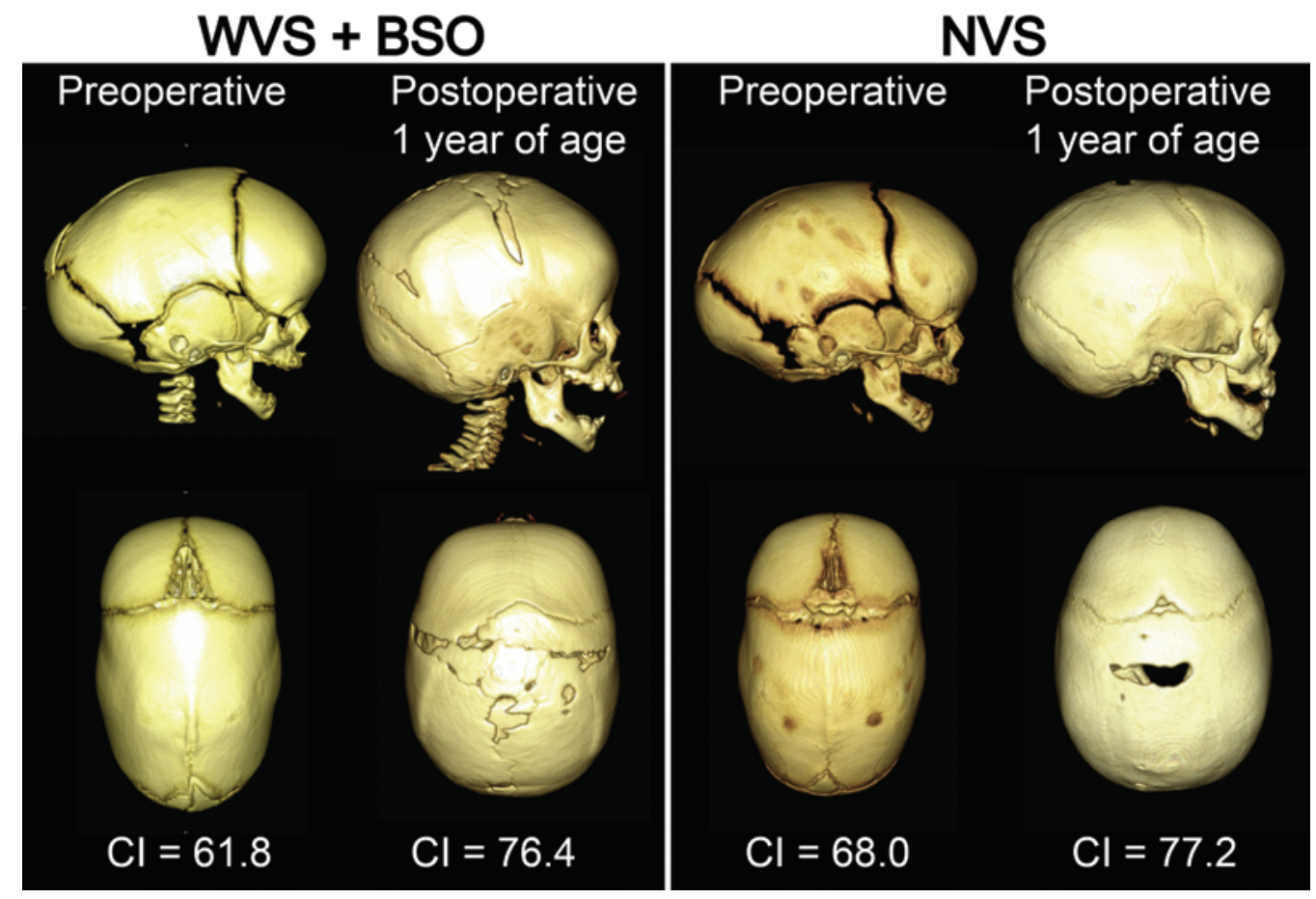

FIG. 3. Three-dimensional CT representative examples of isolated sagittal synostosis before and after WVS+BSO and NVS. Left: Preoperative 3D CT and postoperative 3D CT at 1 year of age after WVS+BSO. Right: Preoperative 3D CT and postoperative 3D CT at 1 year of age after NVS. $\mathrm{Cl}=$ cephalic index. Figure is available in color online only.

\section{References}

1. Berry-Candelario J, Ridgway EB, Grondin RT, Rogers GF, Proctor MR: Endoscope-assisted strip craniectomy and postoperative helmet therapy for treatment of craniosynostosis. Neurosurg Focus 31(2):E5, 2011

2. Jane JA Jr, Lin KY, Jane JA Sr: Sagittal synostosis. Neurosurg Focus 9(3):e3, 2000

3. Jimenez DF, Barone CM: Endoscopic craniectomy for early surgical correction of sagittal craniosynostosis. J Neurosurg 88:77-81, 1998

4. Jimenez DF, Barone CM: Endoscopic technique for sagittal synostosis. Childs Nerv Syst 28:1333-1339, 2012

5. Jimenez DF, Barone CM: Endoscopy-assisted wide-vertex craniectomy, "barrel-stave" osteotomies, and postoperative helmet molding therapy in the early management of sagittal suture craniosynostosis. Neurosurg Focus 9(3):e2, 2000

6. Jimenez DF, Barone CM, Cartwright CC, Baker L: Early management of craniosynostosis using endoscopic-assisted strip craniectomies and cranial orthotic molding therapy. Pediatrics 110:97-104, 2002

7. Jimenez DF, Barone CM, McGee ME, Cartwright CC, Baker CL: Endoscopy-assisted wide-vertex craniectomy, barrel stave osteotomies, and postoperative helmet molding therapy in the management of sagittal suture craniosynostosis. $\mathbf{J}$ Neurosurg 100 (5 Suppl Pediatrics):407-417, 2004

8. Lane LC: Pioneer craniectomy for relief of mental imbecility due to premature sutural closure and microcephalus. JAMA 18:49-50, 1892

9. Lauritzen CG, Davis C, Ivarsson A, Sanger C, Hewitt TD: The evolving role of springs in craniofacial surgery: the first 100 clinical cases. Plast Reconstr Surg 121:545-554, 2008

10. Mackenzie KA, Davis C, Yang A, MacFarlane MR: Evolution of surgery for sagittal synostosis: the role of new technologies. J Craniofac Surg 20:129-133, 2009

11. Ridgway EB, Berry-Candelario J, Grondin RT, Rogers GF, Proctor MR: The management of sagittal synostosis using endoscopic suturectomy and postoperative helmet therapy. J Neurosurg Pediatr 7:620-626, 2011

12. Shah MN, Kane AA, Petersen JD, Woo AS, Naidoo SD, Smyth MD: Endoscopically assisted versus open repair of sagittal craniosynostosis: the St. Louis Children's Hospital experience. J Neurosurg Pediatr 8:165-170, 2011

13. Vogel TW, Woo AS, Kane AA, Patel KB, Naidoo SD, Smyth MD: A comparison of costs associated with endoscopeassisted craniectomy versus open cranial vault repair for infants with sagittal synostosis. J Neurosurg Pediatr 13:324-331, 2014

\section{Disclosures}

Dr. Patel reports that he is a speaker for Hanger Orthotics.

\section{Author Contributions}

Conception and design: Nguyen, Patel, Woo. Acquisition of data: Nguyen, Patel, Woo. Analysis and interpretation of data: Dlouhy, Nguyen, Patel, Hoben, Skolnick, Woo, Smyth. Drafting the article: Dlouhy, Smyth. Critically revising the article: all authors. Reviewed submitted version of manuscript: all authors. Approved the final version of the manuscript on behalf of all authors: Dlouhy. Statistical analysis: Dlouhy, Nguyen, Hoben, Naidoo.

\section{Supplemental Information \\ Previous Presentations}

Portions of this work were presented as an oral presentation at the 43rd Annual Meeting of the AANS/CNS Section on Pediatric Neurological Surgery, December 4, 2014, Amelia Island, Florida.

\section{Correspondence}

Brian J. Dlouhy, Department of Neurosurgery, University of Iowa Hospitals and Clinics, 200 Hawkins Dr., Iowa City, IA 52242. email: brian-dlouhy@uiowa.edu. 